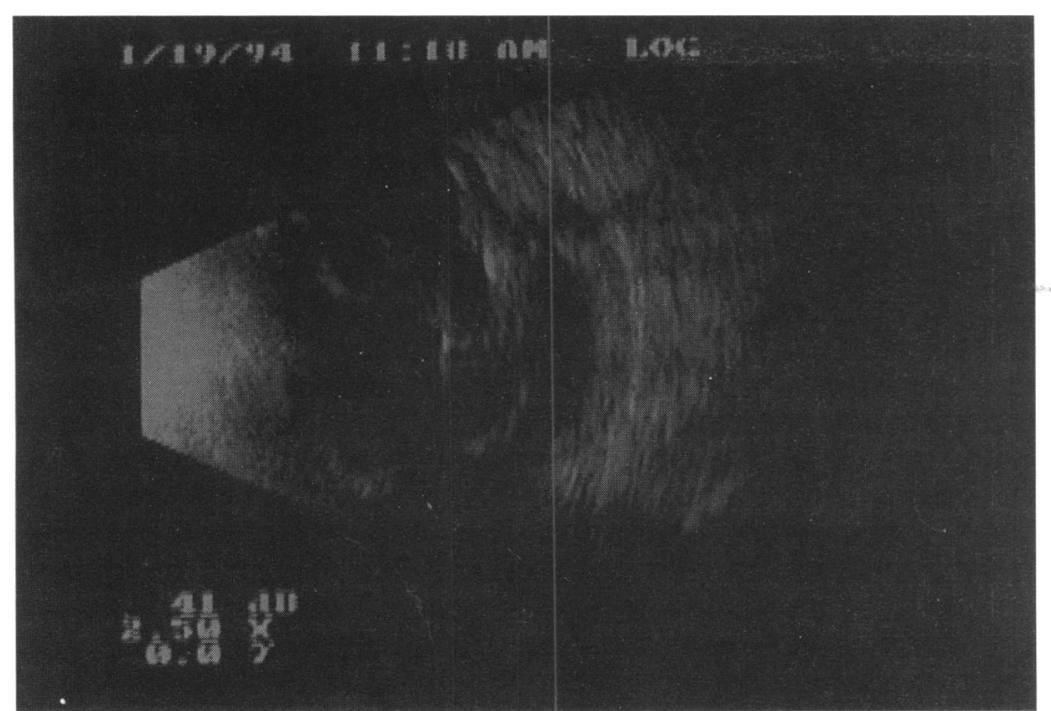

Figure 2 B scan ultrasound left eye. Note hyperechoic area with acoustic shadowing in the posterior segment suggestive of an intraocular foreign body.

correctly diagnosed by CT scan have been described. ${ }^{6}$

Ultrasonography has been advocated in view of its availability, low cost, and high detection rates. One study, ${ }^{3}$ using porcine eyes, reported an overall IOFB detection rate by ultrasound of $93 \%$ compared with $40 \%$ by plain $x$ ray. Significantly, Bryden et al's detection rate for Perspex was $96 \%$. Localisation is, of course, less accurate and the technique may not be applicable in some acutely injured eyes.

This case emphasises the need for a combined approach using plain $x$ ray, CT, and ultrasound in the complete assessment of a penetrating eye injury where an intraocular foreign body is suspected.

1 Roberts-Harry TJ, Davey CC, Jagger JD. Periocular migration of hard contact lenses. Br $₹$ Ophthalmol 1992; 76: tion of

2 Bray LC, Griffiths PG. The value of plain radiography in suspected intraocular foreign body. Eye 1991; 5: $751-4$.

3 Bryden FM, Pyott AA, Bailey M, McGhee CN. Real time ultrasound in the assessment of intraocular foreign bodies. Eye 1990; 4: 727-31.

4 Etherington RJ, Hourihan MD. Localisation of intraocular and intraorbital foreign bodies using computed tomoand intraorbital foreign bodies using

5 LoBue TD, Deutsch TA, Lobick J, Turner DA. Detection and localisation of non-metallic intraocular foreign bodies by magnetic resonance imaging. Arch Ophthalmol 1988; 106: $260-1$

6 Henrikson GC, Mafee MF, Flanders AE, Kriz RJ, Peyman GA. CT evaluation of plastic intraocular foreign bodies. Am $\mathcal{F}$ Neuroradiol 1987; 8: 378-9.

\title{
Crystalline keratopathy from Dieffenbachia plant
} sap

\author{
Benjamin Seet, Wing-Kwong Chan, Chong-Lye Ang
}

Singapore National Eye Centre, Singapore $B$ Seet W-K Chan C-L Ang

Correspondence to: Dr B Seet, Singapore National Eye Centre, 11 Third Hospital Avenue, Singapore 0316 .

Accepted for publication 5 September 1994
We report an unusual ocular injury caused by sap of the Dieffenbachia plant, in which there is acute keratoconjunctivitis associated with needle-like crystals in the cornea. Diagnosis is made from a history of contact with the sap, as well as by the presence of characteristic crystals.

\section{Case report}

A 23-year-old man was cutting bushes of Dieffenbachia (Fig 1) when sap squirted into his right eye. He complained of mild irritation which developed, within a few hours, into severe eye pain associated with redness and mild visual blurring. $\mathrm{He}$ was initially treated by his general practitioner with chloramphenicol eyedrops, and examined by us on the third day after the injury. At this time, he complained that the redness had not resolved, but he was otherwise asymptomatic.

Visual acuity in the right eye was $6 / 7 \cdot 5$. There was mild conjunctival injection and chemosis, as well as slight subconjunctival haemorrhage. The corneal epithelium was intact at the time of examination, but fine refractile needle-like blue crystals were seen within the cornea, extending from the subepithelial region to the posterior stroma. These were distributed predominantly in the interpalpebral and inferior cornea (Fig 2). There was no associated corneal oedema or cellular infiltration and no inflammatory activity within the anterior chamber. No abnormality was detected in the uninjured left eye. The eye was treated with a chloramphenicol dexamethasone combination, prescribed 4 hourly.

The patient remained asymptomatic and the injection and chemosis resolved after 1 week. The corneal crystals were noted to disappear spontaneously over subsequent weeks, with no crystals visible 3 months after the injury. There was no residual corneal scarring or neovascularisation (Fig 3).

\section{Comment}

The Dieffenbachia is a common household plant belonging to the Araceae family. It was 


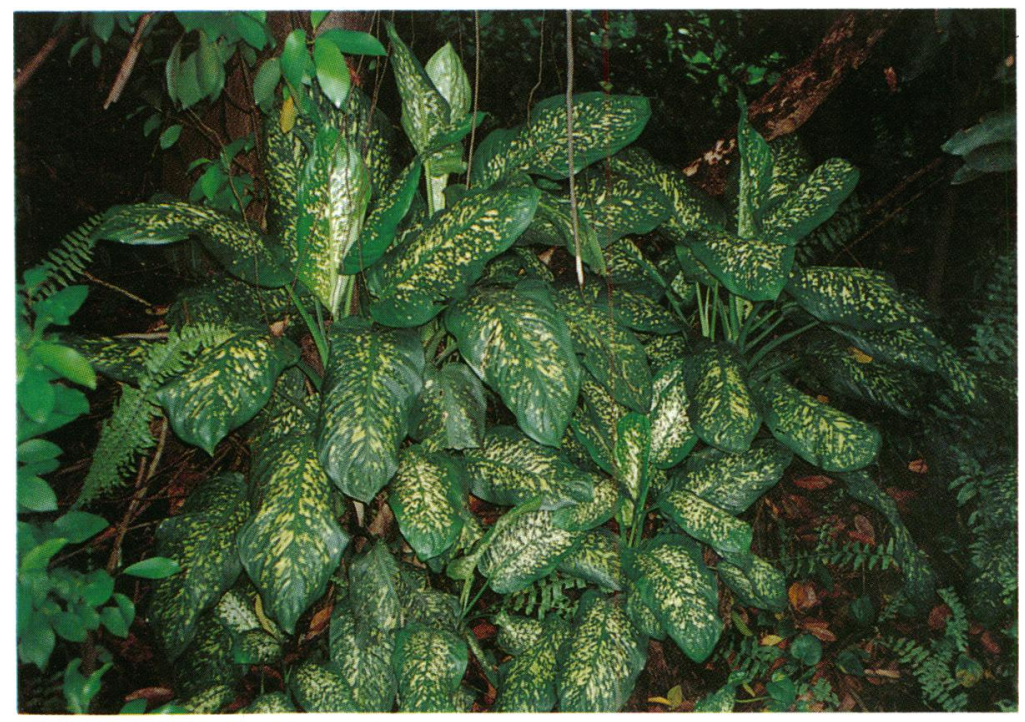

Figure 1 Dieffenbachia sequine.

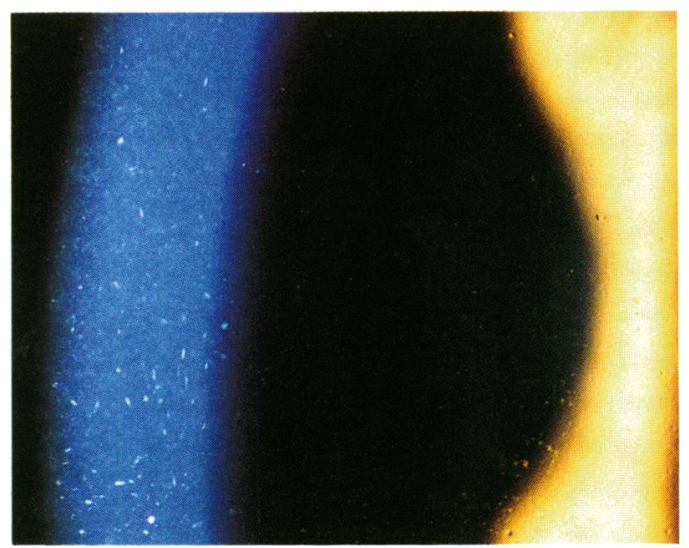

Figure 2 Slit-lamp view showing needle-like crystals in the corneal stroma.

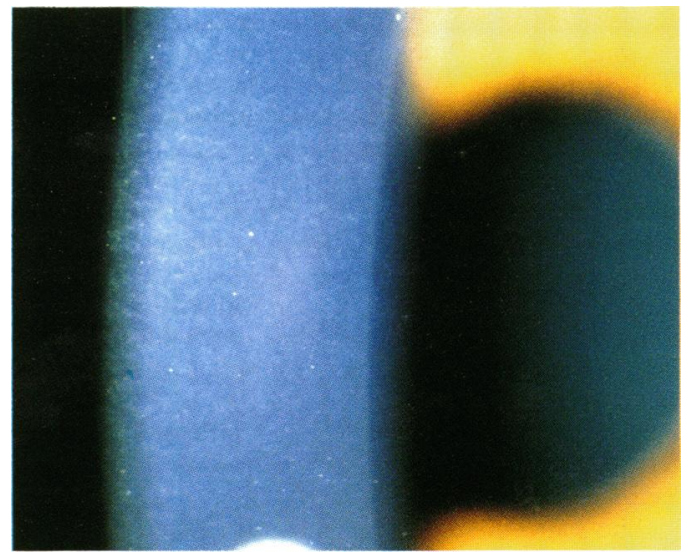

Figure 3 Spontaneous resolution of crystals after 3 months.

and expel the crystals with explosive force. This mechanism has been compared with bullets emerging from a gun ${ }^{6}$ and, together with the rapier-like shape of the crystals, enables easy penetration of oral mucosa and corneal epithelium. This causes mechanical injury to tissues and disrupts the epithelial barrier, allowing penetration of free oxalic acids and plant proteins which result in further chemical injury. The ingenious combination of mechanical and chemical injury contributes to the severity of symptoms in Dieffenbachia poisoning, and explains the presence of crystals deep within the stroma.

To conclude, it is important to point out that other members of the plant family Araceae, such as philodendrons, also contain raphides and can cause similar forms of injury, although ocular involvement is rarely reported.

1 Barnes BA, Fox LE. Poisoning with Dieffenbachia. $\mathcal{f}$ Hist Med 1955; 10: 173-4.

2 Polh RW. Poisoning by Dieffenbachia. JAMA 1961; 177: 812-3.

$3 \mathrm{Lim} \mathrm{KH}$. External eye allergy from sap of Dieffenbachia picta. Singapore Med $\mathcal{F}$ 1977; 18: 176-7.

4 Ellis W, Barfort P, Mastman GJ. Keratoconjunctivitis with corneal crystals caused by the Dieffenbachia plant. Am f Ophthalmol 1973; 76: 143-7.

5 Frohne D, Pfander HJ (translated by Bisset NG). $A$ colour atlas of poisonous plants - a handbook for pharmacists, doctors, toxicologists and biologists. London: Wolfe Publishing, 1984: 56-9.

6 Woodhouse E. Talking of dumbcane. Pac Hortic 1983; 44: 47-8. 